\title{
Impressões sobre o Barroco em uma narrativa de Agustina Bessa-Luís
}

\author{
Viviane Vasconcelos \\ (Universidade Federal Fluminense)
}

\section{RESUMO}

O escritor Severo Sarduy, na última parte do seu livro Barroco, irá dissertar sobre como certas manifestações do barroco ainda são possíveis na contemporaneidade. Uma das maneiras, segundo Sarduy, será a subversão, por exemplo, por meio de uma lógica do desperdício e da superabundância, utilizados num tempo em que a economia vocabular parece prevalecer. Antes de chegarmos à análise do romance, no qual consideramos haver certas resistências ou resíduos barrocos, elucidaremos a perspectiva teórica a ser seguida, a partir de algumas visões sobre o mundo contemporâneo. No romance $A$ Ronda da Noite, da escritora Agustina Bessa-Luís, podemos perceber uma narrativa em que há um exame crítico da experiência dos valores e dos ideais por meio de uma construção em que, seja por meio de procedimentos próprios da escrita, seja pela escolha da relação do livro com o quadro homônino do pintor holandês Rembrandt, há um questionamento constante da condição e da situação humanas em nosso tempo.

PALAVRAS-CHAVE: Barroco; neobarroco; Agustina Bessa-Luís

\section{ABSTRACT}

Severo Sarduy, the writer, in the last pages of his Baroque book will expatiate on certain expressions of the Baroque that are still possible in the contemporary. One way, according Sarduy, would be the subversion, for instance, by a logic of waste and abundance, used at a time when the economy seems to prevail vocabulary. Before we believe that analysis of the romance book have certain resistances or baroque waste, we will elucidate the perspective of being taken from some views on the contemporary world. In the book "The Round of the Night", by Agustina Bessa-Luís, we can see a narrative in which there is a critical examination of the experience of the values and ideals through development that, through its own procedures in writing or by choice of the book with the same title as the painting of the Dutch painter Rembrandt, there is a constant questioning of the human condition of our time.

KEYWORDS: Baroque; neobaroque; Agustina Bessa-Luís 


\section{Definindo o caminho}

A proposta do artigo é refletir, brevemente, sobre alguns procedimentos barrocos em $A$ Ronda da Noite, romance publicado em 2006 pela escritora Agustina Bessa-Luís, nas relações que se estabelecem entre essa literatura e outros sistemas semióticos, como a pintura, e entre o barroco histórico e o barroco como uma cosmovisão. Parece-me relevante, antes de iniciar o percurso, explicitar as razões pelas quais o presente trabalho se direciona a um determinado corpus teórico em detrimento de outros que, em princípio, produzem questionamentos próximos.

Na obra $A$ condição pós-moderna, o filósofo Jean-François Lyotard (1998) decide por chamar "pós-moderna" uma cultura decorrente das modificações trazidas pela crise dos grandes relatos. A pós-modernidade caracteriza-se pela descrença nos "metarrelatos" transformando as grandes narrativas em algo não comunicável. Descreve-nos Lyotard:

(...) considera-se "pós-moderna a incredulidade em relação aos "metarrelatos". É, sem dúvida, um efeito do progresso das ciências, mas este progresso, por sua vez, a supõe. Ao desuso do dispositivo metanarrativo de legitimação corresponde sobretudo a crise da filosofia metafísica e a da instituição universitária que dela dependia. (LYOTARD, 1998, p. 3)

O geógrafo britânico David Harvey, em Condição pós-moderna (1996), entenderá o mundo contemporâneo na condição histórico-geográfica. Por meio da Indústria da produção de imagem, que organiza e impõe o que há de essencial para a experiência da modernidade, é possível notar a modificação do espaço-tempo decorrente da exploração na reprodução da ordem social.

Para o norte-americano Fredric Jameson em Pós-modernismo - a lógica cultural do capitalismo tardio (1996), o pós-moderno é uma nova fase do capitalismo em que existe uma lógica cultural, uma vez que a produção estética estaria ligada à produção de mercadorias. Isso gerou, no processo de modernização, um maior distanciamento entre o humano e a natureza, resultando em uma "segunda natureza" revelada pela cultura.

Tanto em Lyotard, como em Harvey e Jameson, podemos observar uma profunda alteração da relação entre o sujeito e o mundo a partir da decadência dos grandes discursos que sustentaram o mundo na modernidade. De fato, não podemos negar uma época cujo constraste e oscilação sintetizam um tempo marcado pela ambivalência. No entanto, ao longo da história, tais disparidades puderam ser percebidas por diversas vezes na estrutura do tecido social.

José Antonio Maravall, em $A$ cultura do barroco ${ }^{1}$, ao discutir a formação da cultura no século XVII, tendo como referencial para sua minuciosa análise principalmente a Espanha, já aponta para uma discussão sobre a manipulação surgida nos seiscentos. Uma época que, segundo Maravall, leva a um dirigismo das massas mais dinâmico. No período, surgiu uma ideia de que as verdades sobre o mundo teriam que ser proporcionadas aos homens à medida que, ao mesmo tempo, era preciso movê-los em direção aos objetivos da sociedade. A manipulação sobre os homens era mais complexa e seguia uma preocupação pedagógica já que "é preciso incliná-los, movê-los, atraí-los para os objetivos que a sociedade reclama" mas de um "modo tecnicamente adequado" (MARAVALL, 2002, p. 135). O regime absoluto se espalhou por todo o corpo social, reafirmando todas as manifestações de autoridade, fazendo com que a 
"cultura social" estivesse preocupada também em distrair as pessoas, em mantê-las ocupadas por meio dos jogos e espetáculos, conforme observa Maravall:

(...) pretendeu-se, além do mais e principalmente, apoderar-se da direção dos momentos de lazer e de todas aquelas ocasiões nas quais um público ou um conjunto de indivíduos podia colocar-se em contato com uma obra, ou melhor, uma criação humana, e sentir-se, pela experiência desta, um apelo à liberdade. (MARAVALL, 2002, p. 142)

A Europa do século XVII viveu a alteração não só da visão sobre as questões materiais, sociais, econômicas, como também sobre as questões da subjetividade. A regularidade do pensamento no Renascimento se transformou naquele momento em um conflito que se refletiu em grande parte da produção estética produzida nos seiscentos.

No último capítulo de Barroco, o teórico cubano Severo Sarduy descreverá certas práticas do barroco na contemporaneidade. Ao compreendêlo como uma maneira de ruptura à ordem linear sugerida pela organização da realidade, o autor apresenta a ideia de que a elipse ${ }^{2}$ transgride e inverte o que a tradição entendeu durante muito tempo como perfeição.

O barroco ainda hoje, representado sob a imagem da elipse, seria, portanto, uma maneira de questionar, ironizar e ameaçar um tempo cuja linguagem parece servir apenas a um caráter utilitarista e meramente informacional, como escreve Sarduy: "contestação da própria ordem que até aí o estruturava com o seu afastamento e a sua autoridade; barroco onde se recusa qualquer instauração, onde o que se metaforiza é o facto de a ordem ser discutida, o deus julgado, a lei transgredida". (SARDUY, 1999, p. 97)

Algumas das evidências de que o exercício do barroco é o da subversão são notadas em uma superabundância, em um desperdício. Voltando à imagem da elipse, afirmará Sarduy que as duplas acepções conferidas a ela trazem a noção de ausência e não-ausência, significados decorrentes da própria etimologia da palavra:

A elipse, nas suas duplas acepções, surge desenhada em torno de dois centros: um visível (o significante marcado | o sol), diurno, que resplandece na frase barroca; o outro obturado (o significante escondido | o centro virtual da elipse dos planetas), elidido, excluído, sombra. (SARDUY, 1999, p. 68)

Sarduy ainda afirmará que o barroco desestruturou as unanimidades, ocasionando uma revisão nos conceitos que sustentavam formas bem definidas de percepção e pensamento do mundo. Relacionar alguns elementos do barroco histórico com os dias atuais parece ser possível por meio do conceito de história do filósofo Walter Benjamin (1984). Compreendido enquanto ideia, o barroco rompe os limites da localização temporal, no qual normalmente é enquadrado pelos estudos de história da arte. Sendo inesgotável, o barroco está inserido antes e depois do momento histórico e artístico no qual as suas produções, aqui entendidas como fenômenos, se manifestam, e a sua conceitualização corresponde à organização teórica como gênero artístico. Pode-se dizer que a essência do barroco está presente independente da época em que se encontre, permitindo que seja entendido, por extensão, como uma das estruturas fundantes da subjetividade moderna. 
$\mathrm{Na}$ prática, tais características são percebidas em obras de alguns escritores da contemporaneidade, o que fará o teórico italiano Omar Calabrese, por exemplo, reconhecer em nossos dias algumas características do barroco com um novo enfoque, transmutadas na definição de neobarroco. A instabilidade e a mutabilidade são os vocábulos que dão conta de uma realidade díspar, muitas vezes desproposital, que apresenta sinais de uma dissemelhança, de uma divergência.

Calabrese defende o termo neobarroco em lugar de pós-moderno ao perceber que importantes fenômenos que vemos acontecer trazem certas formas do barroco. Não se trata de um retorno à estética barroca, mas sim de entender o barroco como "uma atitude generalizada e uma qualidade formal dos objetos que o exprimem". (CALABRESE, 1988, p. 27)

Após algumas definições que tentam dar conta da contemporaneidade, fundamentais para a tessitura desse artigo, optaremos pelas considerações que entendem o barroco como uma maneira específica de ver o mundo presente até os dias atuais, buscando perceber, então, como certas práticas barrocas são notadas ainda nas produções artísticas e literárias, construídas nas tensões que envolvem a atualidade.

\section{O Barroco e a narrativa de $\boldsymbol{A}$ Ronda da Noite sob o ponto de vista temático}

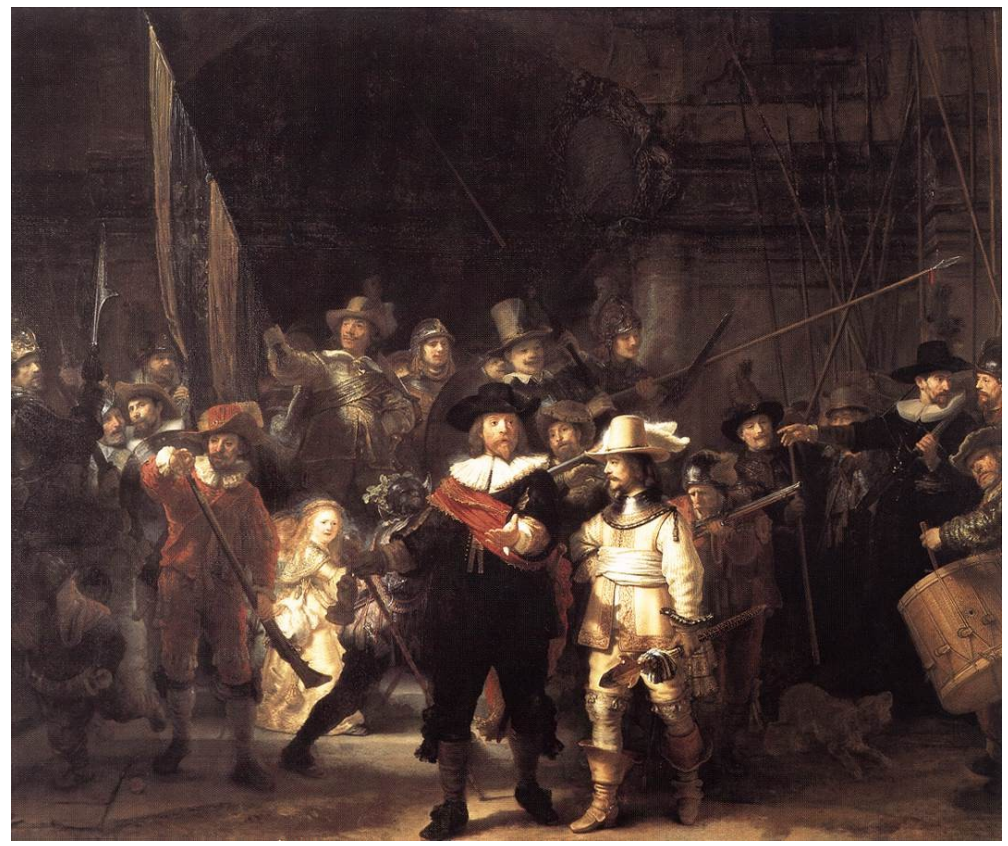

A Ronda Noturna, Rembrandt (1642)

Em 2006, Agustina Bessa-Luís lança $A$ Ronda da Noite e, desde o título, sugere um diálogo com o quadro homônino do pintor holandês Rembrandt. $\mathrm{O}$ romance, ao longo de suas mais de trezentas páginas, se debruça aparentemente sobre a relação entre Martinho Nabasco e a obra de arte de Rembrandt. É curioso notar que, num tempo que parece aniquilar os sentidos e o pensamento crítico, uma escritora resolva ter como tema a observação de uma obra de arte por uma personagem que tece toda a sua trajetória por meio da construção de uma nova realidade instaurada pela arte. 
A começar pelo próprio diálogo do romance com o quadro de Rembrandt, poderíamos realizar uma aproximação temática com o barroco, por ser a obra do artista holandês uma das mais representativas produções artísticas do período. No quadro, observamos certos traços da técnica pictórica do artista que nos conduziriam a uma leitura do período refletida na composição tanto de Rembrandt, como também na de Agustina Bessa-Luís, compreendendo a estratégia da escrita do romance como um jogo entre o pictórico e o literário. Em função da brevidade dessa análise, detenho-me a destacar passagens do percurso de Martinho Nabasco, personagem principal do romance.

No capítulo dedicado a Martinho, de nome Mutante, somos direcionados a uma característica observada por Maravall para descrever o homem dos seiscentos e que nos interessa inicialmente para este trabalho: a variabilidade, ou seja, a mutabilidade que é peculiar na esfera das coisas que estão sujeitas a uma constante mudança e ruína. O historiador nos aponta para um mundo em que as certezas são postas em decadência, um mundo em que nada parece permanecer.

A mudança, de acordo com Maravall, afeta não só as categóricas proposições sobre a existência do homem, como também os elementos naturais que trazem a ideia de eternidade. No mundo do devir, o homem é um peregrino entre as modalidades do real, entre manifestações dessa realidade, posto numa condição de transitoriedade na qual a inconstância se coloca como fundamental para a construção das relações humanas. A instabilidade ou a variação são termos adequados ao desenvolvimento da personagem central, um "hipomaníaco bem caracterizado pela eufória das ideias" (BESSA-LUÍS, 2006, p. 87). Um homem que no início parece ser apático em relação à realidade, deslocado de um mundo a que não consegue adaptar-se. Homem de poucas relações afetivas, que desde criança se detém a analisar cada ação sugerida pelo quadro de Rembrandt. A própria designação de mutante conferida a Martinho soa como uma crítica implícita, uma vez que a personagem era mutante para as exigências mais rotineiras solicitadas pela vida: "se fazia coisas antiquadas era porque guardava nos labirintos do cérebro coisas que executava de forma automática" (BESSA-LUÍS, 2006, p. 100). Dedicou-se aos estudos de filosofia e letras e não investiu afetos nas relações humanas. Sua inconstância não chega a ser um sinônimo de fragilidade, já que por meio da interpretação do quadro acreditava que cada um desempenhava um papel no mundo "como Cristo, nascera num lugar desconhecido para melhor formular um pensamento original" (BESSA-LUÍS, 2006, p. 66). Somos levados a crer que o projeto de vida de Martinho baseia-se na contramão da ideia de um projeto de vida em comum que una todos os seres humanos. O perfil psicológico traçado para Martinho Nabasco foge de um estreitamento de valores que possam identificálo como pertencente ao mundo contemporâneo:

Muitas das suas forças eram poupadas e no seu espírito acumulava razões para vencer. Mas, vencer o quê? Onde estavam os inimigos se não os provocara? Onde estavam os caminhos se não os abria? $\mathrm{O}$ mundo era grande e ele tinha de começar por algum lado. (BESSA-LUÍS, 2006, p. 101)

O narrador questiona, por meio de Martinho, o surgimento de cada etapa da vida como sendo inviolável. Um livro que se inicia falando da morte, quando Martinho e sua avó Maria Rosa estão visitando o túmulo da família no dia de finados, e termina novamente com a morte, descrevendo cada passo da 
vida da protagonista, questiona mais uma vez a existência de parâmetros únicos para os limites da existência. O significado da morte depende inexoravelmente dos valores com os quais a vida se constrói. Um aspecto decisivo será, portanto, a suspensão de uma ideia unilateral para a vida, dotada de potencialidades e pronta para ser transformada em algo sempre valioso.

Romper com essa "santidade" da vida é exatamente ir de encontro a uma vida humana com valor intrínseco. Martinho não participa de um projeto comumente perceptível nos dias atuais: não possui grandes ambições materiais, apesar de ser neto de uma família aristocrata decadente, nunca almejou ter uma família, nunca construiu relações que excedessem os limites do seu isolamento proposital.

Parte das considerações feitas acerca do que é ser homem, se aplicadas à figura de Martinho, aproximaria a personagem da humanidade por pertencer à espécie homo sapiens ou por possuir certos indicadores de humanidade? A inteligibilidade do agir humano em Martinho implica em despertar a consciência de que as opções consistentes do comportamento humano consolidam-se na experiência dos valores, que implacavelmente, para cada indivíduo, constitui o começo da construção da sua própria moralidade individual.

Segundo Horácio Assis, médico da família, tudo em Martinho era resultado de uma "educação de isolamento e falta de competitividade" (BESSA-LUÍS, 2006, p. 85). Era na Ronda da Noite que estava a "libertação do desejo e da morte" (BESSA-LUÍS, 2006, p. 69) da personagem que se dedicava à leitura de obras em inglês e francês do século XVII:

O homem é infeliz enquanto não troca as leis que orientam a vida pública e particular pela virtude criadora da destruição. As suas paixões estavam a ser fixadas nas coisas passadas, coisas que não tinham algum poder sobre ele, que ele pode viciar, se quiser inventar, reconstruir como um puzzle desfeito e voltado a reunir em todas as suas peças que ocupariam outro lugar e não o que lhes fora destinado. Por isso é que a ordem de Banning Cocq não era obedecida. Atrás dele estava uma turba de pessoas felizes por lhe desobedecerem e que não preparavam qualquer cortejo; simplesmente estavam a negar-se a cumprir fosse o que fosse. Um entusiasmo fresco e cheio de actividade saudava a destruição da ordem. Assim, as figuras convencionais dos retratados ficavam tão destituídas de poder que fora isso que provocara o riso dos admiradores de Rembrandt; de repente, acharam-no fora da sua ordem, da sua marcha dos arcabuzeiros, das suas insígnias e bandeiras. Era a epopéia duma total destruição. A destruição necessária e vital em que o homem alimenta a criação que tem a seu cargo. Porém, destruir como no caso das guerras, das torturas, das sevícias brutais sobre o mais fracos, o que ganha um peso primordial é o prazer sexual. Entendendo isso, é preciso que outro consumo da destruição seja efectuado.(BESSA-LUÍS, 2006, p. 310)

O narrador parece oferecer indícios para a reflexão de que o conhecimento do fundamento e do valor do agir humano é um esforço ao qual não se pode renunciar para compreender a vida humana. A conduta de Martinho Nabasco explicita a necessidade da autoafirmação de cada indivíduo 
acerca da legitimidade de seus interesses. Ao renunciar a um projeto de vida coletivo e ao inserir-se à margem de seu tempo, a personagem desenvolve um itinerário de reclusão e de incertezas, aos olhos de uma realidade fundada em certas categorias universais inquestionáveis, mas reafirma uma complexidade comportada pela experiência. A obra de Bessa-Luís provoca ainda o leitor, sob o ponto de vista temático, ao indagar sobre a sua posição no mundo contemporâneo, em primeiro lugar, a partir da descrição de Martinho Nabasco e, em segundo lugar, a partir da ligação entre a personagem e a criação estética.

Em Lições sobre a Analitica do Sublime, Jean-François Lyotard faz uma espécie de nova leitura da Analítica do Sublime, de Immanuel Kant. A noção de sublime em Lyotard está relacionada com a ideia do absoluto, naquilo que a natureza pode representar de inalcançável. A contradição se traduz no sentimento do sublime, na indeterminação; já o belo é apreensível e pode se apresentar na forma do objeto. Portanto, o sentimento sublime pode gerar reações diversas, tais como o prazer, a angústia, a inquietação, já que a ambivalência de sensações é resultado de sua transitoriedade, tal como escreve Lyotard:

A satisfação proporcionada pelo sublime surge 'indiretamente', como um sentimento de dois tempos contrários: as 'forças da vida' sofrem um instante, uma inibição, são retidas, reprimidas; depois são deixadas, expandem-se. (...) A causa dessa angústia transitória, a emoção sublime, não tem, pois, nada de um jogo. Contrariamente ao gosto, o sentimento sublime é uma emoção, uma alternância entre o não e o sim afetivo. Comparado com o prazer do belo, o do sublime é negativo, ele comporta esse recuo, como se o pensamento se chocasse, esbarrasse com aquilo mesmo que o atrai. (LYOTARD, 1993, p. 69).

Para pensar o sublime no mundo contemporâneo, temos que levar em consideração a existência de uma realidade generalizante que impõe uma visão totalizante de culturas e economias. As imagens cada vez mais incidem sobre o cotidiano, influenciando as percepções e subjetividades. Elas muitas vezes impõem um olhar direcionado de uma experiência estética:

Se todas as partes compostas sucessivamente não podem ser compreendidas de uma só vez, então o poder da apresentação que é a imaginação, acha-se ultrapassado. (...) No instante de passar além dessa medida absoluta, a síntese compreensiva da grandeza torna-se impossível, e a qualidade do estado no qual se acha então o pensamento imaginante inverte-se: tem medo deste 'transcendente' que é um além móvel e confuso. (LYOTARD, 1993, p. 104-105)

A narrativa de $A$ Ronda da Noite, sob a perspectiva temática, rejeita inserir-se na produção de uma narrativa mercadológica para ser percebida, sobretudo, sob uma perspectiva melancólica. Segundo Walter Benjamin, a verdade da melancolia, ou a verdade a que ela chega, é uma traição à medida que a contemplação do vazio e da efemeridade das coisas e dos indíviduos, que são transformadas em coisas por não terem mais sentido, é posta em primeiro plano em relação às variadas possibilidades oferecidas pelo mundo: 
De forma tosca e até injustificada, ela exprime, à sua moda, uma verdade, e por causa dela trai o mundo. A melancolia trai o mundo pelo saber. Mas em sua tenaz auto-obsorção, a melancolia inclui as coisas mortas em sua contemplação, para salvá-las. (BENJAMIN, 2004, p.179)

Ora, o que faz Martinho Nabasco senão viver a verdade da melancolia, onde tudo é vazio? Viver essa verdade não resulta somente da relação com o quadro de Rembrandt. A melancólica personagem descreve também um tempo da melancolia. Na voz de Maria Rosa, sua avó, sentimos o tom do desespero: "Como se ele tivesse morrido e ela não o soubesse ainda; quando já todos estivessem informados e preparassem o luto" (BESSA-LUÍS, 2006, p. 20).

Desde o início do romance o leitor acompanha a admiração de Martinho pela obra de arte, transformado-o na sua própria realidade. As figuras e as personagens se misturam durante toda trama, até que no fim o quadro é destruído pela empregada Josefa, que resolve "limpar" o quadro, esfregando-o com água e sabão, restando somente o porta-bandeira, aquele que na obra do pintor aponta para um caminho a ser seguido. A destruição coincide com o fim da vida de Martinho que, ao ter conferido todas as interpretações possíveis à Ronda da Noite, acabou convecido de que teria cumprido o desafio lançado por Rembrandt desde o primeiro contato com a sua produção.

O processo de luto, em Benjamin, parece acontecer por meio da própria linguagem, através da impossibilidade de compor ideias, já que a ausência de sentido acaba com a lógica, e a dor lhe impede de reconstituí-la. Este jogo resulta no deslocamento de interesse do indivíduo por este objeto morto, referencial, para outro objeto, a fim de substituí-lo e, dessa forma, restituir o sentido ao mundo de modo simbólico. Por isso, é possível perceber que, tanto Martinho como nós leitores, diante dessa ausência de uma única possibilidade de leitura, de vida, de escolhas, de projetos, chegamos à conclusão de que conhecer é, sobretudo, percorrer caminhos nunca seguros, pois "ele estava convencido que conseguia. Como toda gente, aliás." (BESSALUÍS, 2006, p. 359)

\section{A escrita da obra}

A imagem é o corpo do nosso pensamento; se a imagem é pertubada, ela tem que encarnar um pensamento doente; as ideias e os desejos são, fatalmente, incapazes de força plástica suficiente para se comunicarem além dos poderes já criados. Os poderes incriados não são da sua conta (BESSA-LUÍS, 2000, p. 281-282).

Temos no texto de Bessa-Luís enigmas difíceis de serem transpostos. $\mathrm{O}$ primeiro, mais evidente, refere-se ao fato de o leitor ser conduzido por uma leitura, prévia, que é, como já vimos, a de Martinho Nabasco sobre o quadro de Rembrandt. Após a interpretação, resta ao leitor de Agustina Bessa-Luís perceber caminhos através dos labirintos construídos ao longo do texto. O título do romance, que toma de empréstimo o título do quadro de Rembrandt, já é um exercício de ekphrásis. Sabemos que o diálogo com a pintura de Rembrandt está presente desde o começo pelo exercício da ambiguidade. Após uma restauração realizada durante a Segunda Guerra Mundial, críticos perceberam que a cena noturna não se adequava à realidade, já que a ação não 
se desenvolve à noite, senão de dia, sendo possível verificar um raio de luz que ilumina as personagens que participam da composição.

Depois, encontramos a estratégia agustiniana de separar a narrativa em capítulos, fazendo supor alguma ordem que depois se esvai em assuntos que retornam, personagens que se confudem e digressões que, aparentemente, se revelam despropositais. Uma das especificidades do romance de Agustina Bessa-Luís, de acordo com Silvina Rodrigues Lopes, é a "crise permanente, desencadeada pela manifestação de uma avalanche incontrolada de acontecimentos e reflexões que o indivíduo não domina mas recebe, das múltiplas realizações da linguagem, literárias e orais". (LOPES, 1992, p. 21)

$\mathrm{Na}$ obra de Bessa-Luís, há imensas descrições das personagens, dos espaços, dos objetos, que por vezes não cumprem nenhum papel no entendimento de uma ação. $\mathrm{O}$ excesso, ao lado da construção que por vezes se apresenta breve, provoca um desencontro com o que já foi lido, desafia a linearidade de um tempo contemporâneo que não cede lugar à contemplação. A linguagem tensionada é posta a serviço de verdadeiras divagações sobre a existência, o tempo, a história ou a filosofia, como podemos obervar quando o narrador fala de Martinho: "Um homem não distingue entre o que é possível e o que é impossível. Enquanto que para Deus, segundo Kant, não há distinção entre o que é possível e o que é real" (BESSA-LUÍS, 2006, p. 106). Um outro exemplo que ilustra tais excessos pode ser notado na fala do narrador ao descrever a passagem do tempo em Maria Rosa, avó de Martinho:

Ela tinha ido, com os anos, ganhando uma patina de velha prata, com os cabelos francamente brancos segundo sua fórmula de que o branco intimida. Às vezes, para se levantar de manhã, tinha que passar de relance os olhos pelo seu guardaroupa para se convencer a sair da cama. Seria outra com outro vestido e outra cor nos lábios. Agora via-se mais ao espelho, o que era sinal de que envelhecia. As mulheres novas guardam a imagem da sua juventude desde pela manhã; as mais velhas têm que corrigir a impressão de que lhes deixou o primeiro olhar do dia. Agora preocupava-se com Judite. (BESSA-LUÍS, 2006, p. 107)

Por vezes, o leitor se depara com figuras de construção que contribuem também para uma leitura lenta, arrastada, com rupturas abruptas, inversões, omissões e repetições de certas ideias ou frases. Assim como no fragmento exposto acima, em determinados momentos o leitor precisa ler atentamente os períodos construídos, pois a narrativa não permite tanto sintática como semanticamente uma leitura sequencial.

O escritor Severo Sarduy conceituará a prática do barroco como uma retórica. A linguagem como espaço do barroco é um lugar do vazio (SARDUY, 1999, p. 54). No bojo de uma reflexão entre literatura e linguagem, entre literatura e ausência, entre literatura e morte, percebemos uma extrema imprecisão de informações no romance provocada pela repetição e pela fragmentada maneira de construção da narrativa.

Descentramento e repetição. O romance de Bessa-Luís se assemelha exatamente ao que Sarduy define como sendo o espaço do barroco "onde a frase do descentramento se desenvolve ao mesmo tempo como repetição e como ruptura". (SARDUY, 1980, p. 63). O espaço literário é, dessa maneira, uma experiência "irracional" e "inconsciente" porque por vezes pode ser a busca pela exuberância das relações de risco. 
- Agora toda a gente se trata por você... Isto pega-se. Não se pegava, mas com esse desleixo de linguagem acudia-se a um despeito profundo. Afinal a revolução não emancipara os pobres, os infelizes, só os tornara menos anónimos. Lamentavam-se como crucificados, mas faltavam os meios para descer da cruz. Tinham a absolvição, mas não o bálsamo que já não era o reino do céu. A impaciência excitava a inveja; a solidão era um novo gueto, evitavam-se as coisas tristes, dava-se preferência ao riso, à barafunda, ao circo, à história projectada com um efeito clínico da sexualidade. As mulheres não perdiam de vista o amor empregando a habilidade para chegar aos fins pretendidos. Faltava porém a exactidão, por falta de meios para obter um resultado fiável. Faltava a confiança que nos é dada como ideia duma perfeição suprema. (BESSA-LUÍS, 2006, p. 107-108)

\section{Considerações parciais}

Seja qual for o ponto de vista filosófico, no qual nos coloquemos, reconhecer-se-á que a falsidade do mundo em que acreditamos é a coisa mais verdadeira e firme que nossa visão pode apreender (NIETZSCHE, 1981, p. 53).

Severo Sarduy entende o nosso tempo como criador de uma estética da transgressão. O barroco seria, portanto, como já citado no início desse trabalho a recusa de uma ordem, uma desproporção, um questionamento. $O$ que podemos parcialmente concluir é que a experiência de leitura do analisado romance de Agustina Bessa-Luís estabelece uma relação através da qual o sujeito contemporâneo, seja por meio da perspectiva temática ou da escrita, descobre-se num outro nível de relação com a realidade, posto que, marcado por uma cisão com uma disposição pragmática da mesma, a verdade se põe sempre permanentemente reconstruída, re-significada. A verdade, sendo sempre uma apresentação, torna-se a cada momento uma nova representação possível. Na literatura, especialmente na de Agustina Bessa-Luís, identificamos traços recorrentes do barroco à medida que notamos na sua escrita um jogo barroco, que é o da simulação, abrindo caminhos para transgressões próprias de uma realidade sempre questionável. E uma das conclusões para a construção dessa estratégia pode vir da autora, ao falar sobre sua narrativa: "Escrevo para desiludir com mérito, que é a maneira de se fazer lembrar com virtude" (BESSA-LUÍS, 2000, p. 15).

\section{NOTAS}

1. Para Maravall, o barroco é "conceito de época", que não pode repetir-se em outros momentos da história. E um fenômeno que teve forte influência na península ibérica, sobretudo na Espanha. 2. Na citada obra de Severo Sarduy, ainda nos primeiros capítulos, o autor desenvolve o conceito de que a passagem de Galileu a Kepler é a do círculo à elipse e como essa imagem da elipse foi preponderante para que possa ser pensado o tempo ao qual o barroco pertence.

3. Imagem retirada da página do Rijksmuseum, onde encontra-se o quadro:

http://www.rijksmuseum.nl/aria/aria_assets/SK-C-5?lang=en. Acesso em 12/12/2008. 


\section{REFERÊNCIAS BIBLIOGRÁFICAS}

BESSA-LUÍS, Agustina. Contemplação Carinhosa da Angústia. 2. ed. Seleção e introdução de Pedro Mexia. Lisboa: Guimarães Editores, 2000. . A Ronda da Noite. Lisboa: Guimarães Editores, 2006.

BENJAMIN, Walter. Origem do drama barroco alemão. Tradução, apresentação e notas de Sérgio Paulo Rouanet. São Paulo: Brasiliense, 1984.

CALABRESE, Omar. A idade neobarroca. Lisboa: Edições 70, 1988.

HARVEY, David. Condição Pós-Moderna: uma pesquisa sobre as origens da mudança cultural. São Paulo: Loyola, 1996.

JAMESON, Fredric. Pós-modernismo. A lógica cultural do capitalismo tardio. São Paulo: Ed. Ática, 1996.

LYOTARD, Jean-François. A condição pós-moderna. Rio de Janeiro: José Olympio, 1998.

. Lições sobre a analítica do sublime. São Paulo: Papirus, 1993.

LOPES, Silvina Rodrigues. Agustina Bessa-Luis: as hipóteses do romance. Rio Tinto: Asa, 1992.

MARAVAlL, J. A. A cultura do Barroco. Análise de uma estrutura histórica. Tradução: Silvana Garcia. São Paulo: Edusp,1997.

NIETZSCHE, Friedrich. Além do bem e do mal. São Paulo: Hemus Ed. 1981.

SARDUY, Severo. Barroco. Tradução de Maria de Lurdes Júdice e José Manuel de Vasconcelos. Lisboa: Vega, 1989. 